\title{
Novedades Legislativas AÑO 2014
}

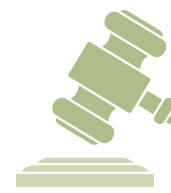

- Ley Orgánica del Poder Legislativo.

Decreto \# 363-2013;

Gaceta \# 33,335 del 22de Enero del 2014

- Ley de Limitación de Servicios de Telefonía Movil Celular y Comunicaciones Personales (CPS) en Centros Penales a nivel nacional.

Decreto \# 255-2013

Gaceta \# 33,343 del 31 de enero del 2014

- Ley de Patronatos y Asociaciones Comunitarias.

Decreto \# 252-2013

Gaceta \# 33,351 del 10 de Febrero del 2014

- Ley de Protección de los Hondureños Migrantes y sus familiares.

Decreto \# 106-2013

Gaceta \# 33,356 del 15 de Febrero del 2014

- Ley para la Promoción y Fomento del Desarrollo Científico, Tecnológico y la Innovación.

Decreto \# 276-2013

Gaceta \# 33,356 del 15 de Febrero del 2014

- Ley de Evaluación, Acreditación y Certificación de la Calidad y Equidad de la Educación.

Decreto \# 265-2013

Gaceta \# 33,357 del 17 de Febrero del 2014

- Ley de Protección de la Soberanía del Espacio Aéreo

Decreto \# 347-2013

Gaceta \# 33,369 del 3 de Marzo del 2014 
- Ley General de Superintendencia para la aplicación de Pruebas de Evaluación de Confianza.

Decreto \# 254-2014

Gaceta \# 33,372 2014 del 6 de Marzo de 2014

- Ley para la Clasificación de Documentos Públicos relacionados con la Seguridad y Defensa Nacional.

Decreto \# 418-2013

Gaceta \# 33,373 del 7 de marzo de 2014

- Ley de Vacunas de la República de Honduras.

Decreto \# 288-2013

Gaceta \# 33,389 del 26 de Marzo de 2014

- Ley de Financiamiento de Viviendas a Docentes.

Decreto \# 401-2013

Gaceta \# 33,389 del 26 de abril de 2014

- Ley Donación y Transplante de Organos Anatómicos en Seres Humanos.

Decreto \# 329-2013

Gaceta \# 33, 412 del 26 de Abril de 2014

- Ley del Consejo Económico Social.

Decreto \# 292-2013

Gaceta \# 33,392 del 29 de Marzo de 2014

- Ley de Empleo por Hora.

Decreto \# 354-2013

Gaceta \# 33,393 del 31 de Marzo de 2014

- Ley del Instituto de Jubilaciones y Pensiones de los Empleados y Funcionarios del Poder Ejecutivo. (INJUPEMP)

Decreto \# 357-2013

Gaceta \# 33, 398 del 5 de Abril de 2014 
- Ley de Fortalecimiento de la Camaricultura.

Decreto \# 335-2013

Gaceta \# 33,403 del 11 de abril del 2014

- Ley de la Lengua de Señas Hondureña. (LESHO)

Decreto \# 321-2013

Gaceta \# 33,433 del 22 de Mayo del 2014

- Ley para la Protección, Beneficios y Regularización de la Actividad Informal.

Decreto \# 318-2013

Gaceta \# 33,436 del 26 de Mayo del 2014.

- Ley de Recompensa.

Decreto \# 21-2014

Gaceta \# 33,452 del 13 de Junio del 2014

- Ley de Protección Especial de Funcionarios y Exfuncionarios de Riesgo Extraordinario.

Decreto \# 323-2013

Gaceta \# 33,467 del 1 de Julio de 2014

- Ley para la Generación de Empleo, Fomento a la Iniciativa Empresarial Formalizacion de Negocios y Proteccion a los Derechos de los Invesrsionistas. Decreto \# 284-2013

Gaceta \# 33,445 del 5 de Junio del 2014

- Ley General de la Industria Eléctrica.

Decreto \# 404-2013

Gaceta \# 33,431 del 20 de Mayo del 2014

- Ley de Compras Eficientes y Transparentes a traves de Medios Electrónicos. Decreto \# 36-2013

Gaceta \# 33,497 del 5 de Agosto del 2014 